\title{
Effect of Varied Oxygen Levels on the Oxidation of a Magnetite Pellet Bed during Pot Furnace Induration
}

\author{
Anna ERIKSSON, ${ }^{1) *}$ Charlotte ANDERSSON, ${ }^{1)}$ Hesham AHMED, ${ }^{1)}$ Anders DAHLIN, ${ }^{21}$ \\ Telkicherla Kamesh Sandeep $\mathrm{KUMAR}^{3)}$ and Pär SEMBERG ${ }^{3)}$ \\ 1) MiMeR, Div. of Minerals and Metallurgical Engineering, Luleå University of Technology, SE-971 87, Luleå, Sweden. \\ 2) Luossavaara-Kiirunavaara Aktiebolag (LKAB), SE-983 81, Malmberget, Sweden. \\ 3) Luossavaara-Kiirunavaara Aktiebolag (LKAB), SE-971 28, Luleå, Sweden.
}

(Received on August 7, 2020; accepted on December 8, 2020; J-STAGE Advance published date: February 21, 2021)

\begin{abstract}
An excess amount of oxygen originating from hydrogen production is likely to be available as part of the HYBRIT (Hydrogen Breakthrough Ironmaking Technology) initiative, aimed at producing fossil-free steel by replacing coking coal with hydrogen. Oxygen enrichment during magnetite pellet induration can lead to reduced fuel amounts and increased productivity. Induration of magnetite iron ore pellets liberates considerable amounts of heat when magnetite is oxidised to hematite. Elevated oxygen levels in the process gas are expected to promote the oxidation reaction, resulting in increased process efficiency. However, more information is required to enable the transition towards a higher oxygen level process and improved production rate, while maintaining the metallurgical properties of the pellet bed. In this study, interrupted pot furnace experiments were conducted on a magnetite pellet bed (approximately $100 \mathrm{~kg}$ ) at Luossavaara-Kiirunavaara Aktiebolag to investigate the effect of oxygen levels at approximately 6\%, 13\%, and $30 \% \mathrm{O}_{2}$. Temperature profiles are measured and pellet properties (compression strength, porosity, oxidation degree, microstructures) are analysed at different bed heights. The higher oxygen level (approximately $30 \% \mathrm{O}_{2}$ ) intensifies the oxidation reaction, resulting in increased temperature, oxidation rate and compression strength across the vertical bed height. Three different pellet oxidation profiles are identified, namely, homogenous oxidation across the pellet, complete oxidation of the pellet shell and an unreacted core with a sharp/distinct interface, and partial oxidation of the pellet shell and an unreacted core. A higher oxygen level results in an increased oxidation rate, while the temperature controls the pellet oxidation profile.
\end{abstract}

KEY WORDS: oxygen enrichment; magnetite pellet bed; oxidation; pot furnace; induration; fossil-free ironmaking.

\section{Introduction}

Owing to the current transition of Swedish steel production to a hydrogen-based system, led by Hydrogen Breakthrough Ironmaking Technology (HYBRIT), the joint venture between Luossavaara-Kiirunavaara Aktiebolag (LKAB), SSAB and Vattenfall, which aims to replace coking coal with hydrogen, an excess amount of oxygen originating from hydrogen production is likely to be available. ${ }^{1)}$ The excess oxygen could potentially be used for iron ore pellet induration, and thereby improve the process efficiency in terms of fuel consumption and productivity. One of the challenges along this path will be to maintain product quality. The main raw material used in Scandinavian steel production is iron ore pellets. In Sweden,

\footnotetext{
* Corresponding author: E-mail: anna.eriksson@1tu.se
}

the mining company LKAB produce both blast furnace and direct reduction pellets. Two main methods for pellet production are used, namely, the straight-grate and the grate-kiln processes. In both cases, a large pellet bed is transported through different zones while being exposed to an atmosphere with varying temperatures (room temperature to $1300^{\circ} \mathrm{C}$ ) and a varied oxygen level (approximately $16 \%$ to $18 \% \mathrm{O}_{2}$ in the pre-heating zone ${ }^{2)}$ ). When being transported, the pellets are dried, oxidised and sintered, which is known as induration. Oxidising magnetite ore to hematite ${ }^{3)}$ releases considerable amounts of heat. Promoting this exothermic reaction by increasing the oxygen level, rather than by fuel, would contribute to reducing greenhouse gas emissions from the industry, which is in line with the Paris Climate Agreement signed by the Government of Sweden in 2015.,5)

The oxidation reaction (Eq. (1)) is highly exothermic, ${ }^{3)}$ 
releasing approximately $498 \mathrm{~kJ} / \mathrm{kg}$ of oxidised magnetite, $\left.{ }^{6}\right)$ and is favoured by an increased temperature and oxygen partial pressure. The surplus energy originating from the exothermic reaction can be utilised in the process and, according to Forsmo, ${ }^{7}$ accounts for more than two thirds of the total energy demand of the LKAB induration process.

$$
2 \mathrm{Fe}_{3} \mathrm{O}_{4}+\frac{1}{2} \mathrm{O}_{2}=3 \mathrm{Fe}_{2} \mathrm{O}_{3}
$$

Oxidation of a magnetite pellet, like most gas-solid reactions of porous solids, occurs through the following steps: ${ }^{8,9)}$

i) Transfer of oxygen molecules from the bulk gas to the pellet surface,

ii) Diffusion of oxygen molecules through the macropores within the pellet, and

iii) Chemical reaction at the surface of the particles, including oxygen adsorption, followed by a transfer of the product by solid-state diffusion.

The oxidation of magnetite pellets and particles has been extensively investigated since the start of the commercial production of iron ore pellets, ${ }^{3,10-22)}$ and models have been developed and used to describe how oxidation occurs at the single pellet and particle scale..$^{8,15,21,23-25)}$ The grain model ${ }^{8)}$ appropriately describes oxidation at the single pellet scale. This model describes the gas-solid reactions of porous solids by combining numerous previously existing models into one general model. The model depicts a pellet as individual particles surrounded by pores (macropores). Gas diffuses via these pores to reach the surface of each particle and the reaction starts. It is assumed that the individual particles are non-porous and that the reaction on a particle scale occurs according to the shrinking core model, also known as the 'sharp-interface model'. ${ }^{8,23}$ The reaction at the pellet scale (in this case oxidation) can be described as the result of three different regimes:

i) When solid-state diffusion controls the overall reaction: this leads to the homogenous oxidation of the entire pellet, as pore diffusion is not rate limiting.

ii) When pore diffusion controls the overall reaction: this leads to complete oxidation of the pellet shell, forming a sharp reaction interface oxidation front and an unreacted core, that is, oxidation as described by the shrinking core model.

iii) When both solid-state diffusion and pore diffusion progress at a comparable rate (mixed-control): this leads to a pellet with completely oxidised particles at the pellet shell, partially oxidised particles in the intermediate section and an unreacted core.

Several process and material parameters influence the oxidation process and, consequently, the pellet properties. It is known that early and homogenous oxidation prior to sintering is advantageous because it increases pellet strength, ${ }^{11)}$ and the oxygen level $\left(\mathrm{p}_{\mathrm{O}_{2}}\right)$ is expected to influence the oxidation kinetics. ${ }^{3,13,15,25)}$ Researchers have investigated the effect of the two major parameters, namely, oxygen level and temperature, on single pellets at isothermal conditions. Edström ${ }^{13)}$ and Papanastassiou and Bitsianes ${ }^{15)}$ concluded that the oxidation rate increases significantly by increasing the oxygen levels at higher temperatures (at $1000^{\circ} \mathrm{C}$ and $1230^{\circ} \mathrm{C}$, respectively). Microscopic investigation of pellets oxidised at tempera- tures $>1000^{\circ} \mathrm{C}$ indicate that oxidation of single pellets follows the shrinking core mechanism, that is, the formation of a sharp reaction interface between the oxidised shell and the unreacted magnetite pellet core. ${ }^{15)}$ Whereas, at lower temperatures $\left(600^{\circ} \mathrm{C}\right.$ and $\left.800^{\circ} \mathrm{C}\right)$ and $16 \%-21 \%$ $\mathrm{O}_{2}$, the pellet is more homogenously oxidised although the larger particles are not completely oxidised. ${ }^{2,10,21)}$ Cooke and $\mathrm{Ban}^{10)}$ performed isothermal tests for $30 \mathrm{~min}$ in air at $100-1200^{\circ} \mathrm{C}$, and observed dense magnetite cores in the pellets at $1100^{\circ} \mathrm{C}$ and $1200^{\circ} \mathrm{C}$, which they believed hindered the oxidation rate at these temperatures. Ilmoni and Uggla $^{12)}$ instead emphasised the effect of time duration at each temperature on the oxidation rate.

Pape et al. ${ }^{16)}$ reported that the residence time of the bed in the pre-heating zone is too short for sufficient oxidation. Haas et al. ${ }^{18)}$ then emphasised the importance of identifying the local conditions of the induration processes where the injection of a gas with an increased oxygen level would most contribute to improved production rates. They performed mini-pot experiments, with $2 \mathrm{~kg}$ of pellets per bed, simulating the effect of varied oxygen levels $(6 \%, 15 \%$, and $30 \% \mathrm{O}_{2}$ ) on commercial induration. One of their observations from the $30 \% \mathrm{O}_{2}$ tests was the effective enhancement of oxidation at approximately $1000^{\circ} \mathrm{C}$.

Scale is the key to investigate induration in realistic nonisothermal conditions. The current knowledge on the effect of different oxygen levels on oxidation is based on smallscale experiments. The effect of varied oxygen levels on a large bed scale, such as the resulting oxidation gradient and trends on exothermic heat increase, is thus unknown and well-researched oxidation mechanisms remains to be established from a bed perspective. The aim of this study is to

i) investigate and identify the oxidation mechanisms along a large magnetite pellet bed at various oxygen levels and temperature profiles, and

ii) determine the influence of oxygen partial pressure and temperature at comparable local thermal histories in the bed and across experiments with varying conditions.

We examine magnetite pellets produced at pilot scale at LKAB using an interrupted pot furnace experimental method at an approximate scale of $100 \mathrm{~kg}$ of pellets per bed.

\section{Method}

We examined the influence of varied oxygen levels on the oxidation of a magnetite pellet bed during induration through interrupted pot furnace experiments. Magnetite concentrate was obtained from LKAB, and Table 1 shows particle size data. The concentrate was mixed with additives (dolomite, limestone and quartzite) and bentonite (as a binder, 0.6 mass\%) in a Eirich R09/T pilot scale mixer

Table 1. Magnetite concentrate particle size data.

\begin{tabular}{ccc}
\hline \multicolumn{3}{c}{ Particle size data } \\
\hline$<45 \mu \mathrm{m}$ & $<63 \mu \mathrm{m}$ & $<90 \mu \mathrm{m}$ \\
$\%$ & $\%$ & $\%$ \\
69.4 & 79.1 & 89.3 \\
\hline
\end{tabular}


with a capacity of $240 \mathrm{~kg}$. Green pellets were produced from approximately $200 \mathrm{~kg}$ of iron ore concentrate in a batch process pilot-sized disc pelletiser. The desired fraction (10-12.5 $\mathrm{mm}$ ) of green pellets was continuously collected from rollerscreens. The green pellets contained a final moisture content of $8.5 \mathrm{mass} \%$, an average chemical composition of 70.1 mass \% Fe $\left(22.1 \% \mathrm{Fe}^{2+}\right), 0.74$ mass $\% \mathrm{SiO}_{2}, 0.91$ mass\% $\mathrm{CaO}$ and 0.67 mass $\% \mathrm{MgO}$. The green pellet porosity was on average, considering all experiments, 30.2\%. Propane combustion provided the heat of the ingoing gas during the induration, and the oxygen level was determined by the selected amounts of ingoing air, as well as nitrogen or oxygen. Before each experiment, the physical properties of the green pellets (moisture, drop test, compression strength and pellet size distribution) were measured to ensure the desired quality, then a bed of approximately $100 \mathrm{~kg}$ green pellets was loaded in the pot.

The total bed height was approximately $45 \mathrm{~cm}$, and thermocouples installed at six different bed heights, as depicted in Fig. 1, continuously measured the temperatures across the vertical direction of the bed. Each thermocouple measured the temperature $5 \mathrm{~cm}$ from the furnace wall. We refer to the temperature profile as the measured temperature as a function of time. Figure 1 depicts the positions of the installed thermocouples as a percentage of the total bed height. Thermocouples A, B, C, D, E, and F refer to the measured temperature profiles at $100 \%, 76 \%, 51 \%, 27 \%, 15 \%$, and $5 \%$ of the bed height, respectively. The thermocouple $\mathrm{F}$ was complemented with a second thermocouple (F1) at the same bed height, to measure the temperature at the centre of the bed. The hearth layer was at $0 \%$ of the bed height (Fig. 1). The three zones of drying and pre-heating (zone 1), varied oxygen level (zone 2) and cooling (zone 3) describes the induration of each experiment.

In zone 1, the bed was first dried (up draft, UD) with air, until thermocouple A reached $150^{\circ} \mathrm{C}$, then the bed was further dried (down draft, DD) for $120 \mathrm{~s}$ by air at $180^{\circ} \mathrm{C}$.

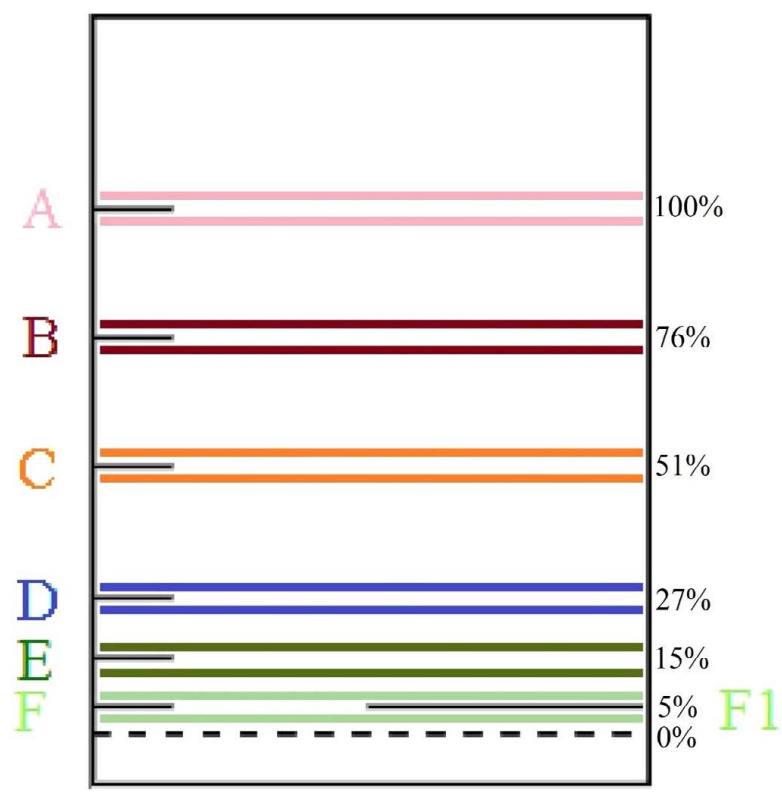

Fig. 1. Schematic illustration of the pot furnace and position of thermocouples A, B, C, D, E, and F as a percentage of total bed height. (Online version in color.)
The combination of UD and DD was chosen to optimise the drying and avoid condensation at lower bed heights. After drying, the bed was pre-heated (DD) gradually from $500^{\circ} \mathrm{C}$ to $800^{\circ} \mathrm{C}$ for $240 \mathrm{~s}$, and then the ingoing gas temperature was held at $800^{\circ} \mathrm{C}$ (DD) for 300 s. During pre-heating, the ingoing gas oxygen level was kept as low as possible (approximately 3\%). After zone 1, the temperature measured at the top of the bed was approximately $800^{\circ} \mathrm{C}$ (at $100 \%$ bed height), whereas the corresponding temperature at the bottom of the bed was approximately $170^{\circ} \mathrm{C}$ (at $5 \%$ bed height). A separate pre-experiment determined the oxidation degree and moisture at the end of zone 1. Table 2 summarises the initial conditions before the start of zone 2 (example data from the pre-experiment) and shows the oxidation degree gradient in the bed. The pellets at the bottom of the bed exhibited properties similar to green pellets, whereas the pellets at the top of the bed had begun to oxidise (approximately $28 \%$ and $14 \%$ oxidation degree at thermocouple A and $\mathrm{B}$, respectively).

Gas with a predefined oxygen level and constant temperature was introduced (DD) in zone 2 for $725 \mathrm{~s}$ at a constant gas flow of $250 \mathrm{~kg} / \mathrm{h}$. After zone 2, the experiment was interrupted by cooling (UD) in zone 3 with nitrogen gas until thermocouple A reached $200^{\circ} \mathrm{C}$, and then cooling continued (UD) with air. The gas direction (UD) during cooling was chosen to preserve the conditions at lower bed heights to the greatest extent by avoiding the additional heat transfer from upper bed heights associated with using down draft direction. Three separate experiments were conducted where the gas temperature was set to $800^{\circ} \mathrm{C}$ and the oxygen level to approximately $6 \%, 13 \%$ and $30 \% \mathrm{O}_{2}$, respectively. Whereas, one experiment was performed at gas temperature of $1100^{\circ} \mathrm{C}$ and an oxygen level of approximately $6 \% \mathrm{O}_{2}$. Each experiment was replicated once or twice, that is, one replicate for the oxygen level at approximately $6 \%$ and $13 \% \mathrm{O}_{2}$, respectively, and two replicates at approximately $30 \% \mathrm{O}_{2}$. Figure 2 illustrates the ingoing gas temperatures during the experiments, and Table $\mathbf{3}$ shows an overview of the experiments. The three oxygen levels were chosen based on the current design specifications of the equipment, which allowed for approximately $6 \%$ and $30 \% \mathrm{O}_{2}$ as the lower and higher level, respectively, when the ingoing gas flow rate is at $250 \mathrm{~kg} / \mathrm{h}$. Reported oxygen levels during pre-heating in commercial induration processes (approxi-

Table 2. Initial conditions of the bed just before the start of zone 2 (data from a pre-experiment).

\begin{tabular}{ccccc}
\hline $\begin{array}{c}\text { Initial } \\
\text { conditions }\end{array}$ & Bed height & Temperature & $\begin{array}{c}\text { Degree of } \\
\text { oxidation }\end{array}$ & Moisture \\
\hline Thermocouple & $\%$ & ${ }^{\circ} \mathrm{C}$ & $\%$ & $\mathrm{wt} . \%$ \\
\hline A & 100 & 800 & 28 & 0 \\
B & 76 & 610 & 14 & 0 \\
C & 51 & 375 & 4 & 0 \\
D & 27 & 205 & 1 & 0 \\
E & 15 & 190 & Not applicable & 0 \\
F & 5 & 170 & Not applicable & 0 \\
Hearth layer & 0 & & & \\
\hline
\end{tabular}




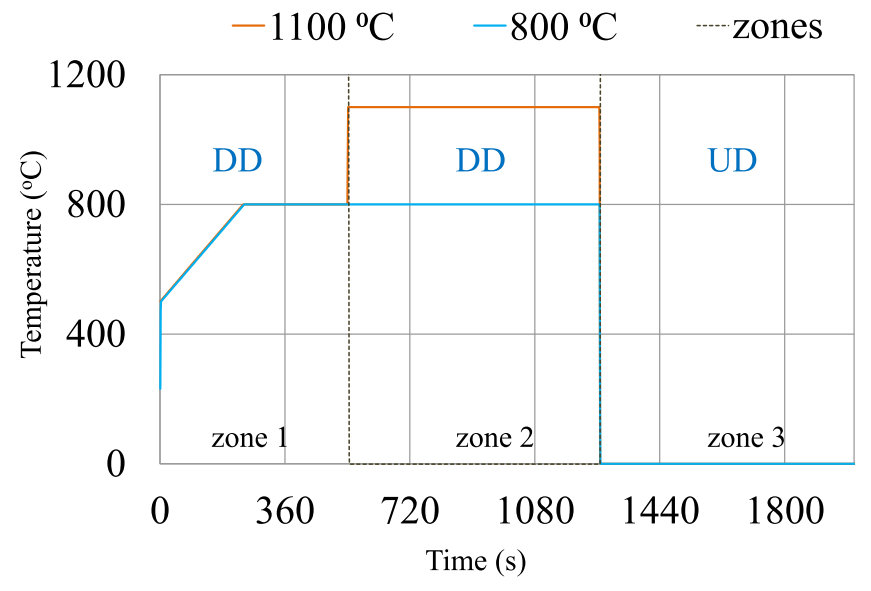

Fig. 2. Overview of the ingoing gas temperature during the experiments. Zone 1: $240 \mathrm{~s}$ with an ingoing gas at 500 $800^{\circ} \mathrm{C}(\mathrm{DD})$ and then $300 \mathrm{~s}$ at $800^{\circ} \mathrm{C}(\mathrm{DD})$. Zone 2: varied oxygen level for $725 \mathrm{~s}$ and ingoing gas temperature at $800^{\circ} \mathrm{C}$ or $1100^{\circ} \mathrm{C}$ (DD). Zone 3: cooling (UD). (Online version in color.)

Table 3. Overview of experiments: total number of experiments (including replicates) and experimental settings in zone 2 .

\begin{tabular}{cccc}
\hline \multicolumn{4}{c}{ Overview of experiments } \\
\hline $\begin{array}{c}\text { No. of } \\
\text { experiments }\end{array}$ & $\begin{array}{c}\text { Oxygen level of } \\
\text { the ingoing gas } \\
(\mathrm{DD})\end{array}$ & $\begin{array}{c}\text { Temperature of } \\
\text { the ing. gas } \\
(\mathrm{DD})\end{array}$ & $\begin{array}{c}\text { Gas flow rate of } \\
\text { the ing. gas } \\
(\mathrm{DD})\end{array}$ \\
\hline $\mathrm{oO}_{2}$ & ${ }^{\circ} \mathrm{C}$ & $\mathrm{kg} / \mathrm{h}$ \\
\hline 2 & $\approx 6$ & 800 & 250 \\
2 & $\approx 13$ & 800 & 250 \\
3 & $\approx 30$ & 800 & 250 \\
3 & $\approx 6$ & 1100 & 250
\end{tabular}

mately $\left.16-18 \% \mathrm{O}_{2}\right)^{2)}$ motivated the choice of the oxygen level of approximately $13 \% \mathrm{O}_{2}$, the slightly lower level was preferred because it allowed for the investigation of a greater variation.

\subsection{Temperature Profiles}

Figure 3 shows the measured temperature profile (X-Y plot) at $27 \%$ of the bed height (thermocouple D) in the pellet bed from the experiment with an ingoing gas at $800^{\circ} \mathrm{C}$ and approximately $30 \% \mathrm{O}_{2}$ in zone 2 . Temperature profiles and a selection of parameters are used to describe the local thermal histories at different bed heights, and Fig. 3 and Table 4 provides an example. MaxT refers to the maximum measured temperature in zone $2, d T / d t_{400-\operatorname{Max} T}$ refers to the heating rate from $400^{\circ} \mathrm{C}$ to $\operatorname{MaxT}$ in zone 2 and the time

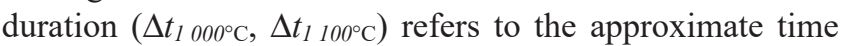
that the measured temperatures were at or above either $1000^{\circ} \mathrm{C}$ or $1100^{\circ} \mathrm{C}$ (zone 2 and zone 3 ).

\subsection{Sampling and Characterisation}

Batches of pellet samples (approximately $4 \mathrm{~kg}$ pellets) were collected at the same bed heights as the installed thermocouples (A-F). To obtain representative sub-samples, the samples were manually sieved to $10.0-12.5 \mathrm{~mm}$ according to ISO standard 4700: 2015 ${ }^{26)}$ and then divided using a

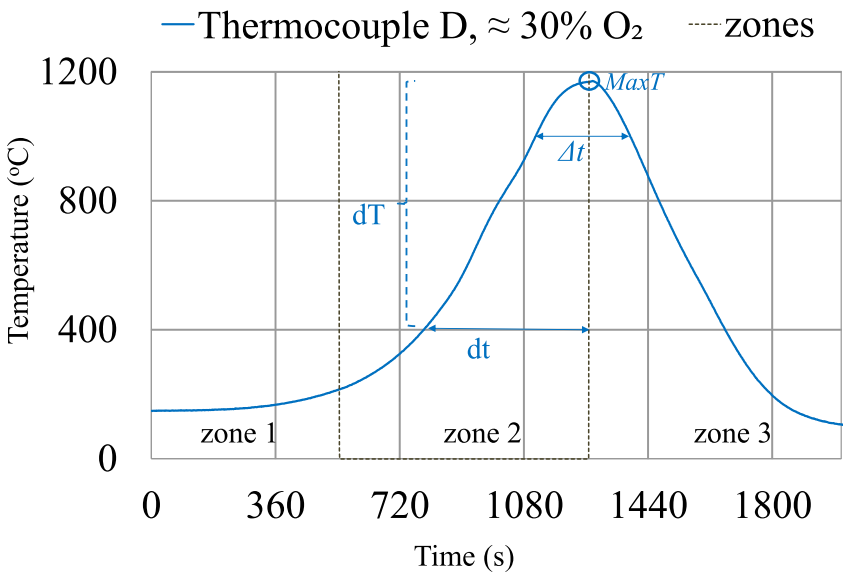

Fig. 3. Example of a temperature profile in a pellet bed (at $27 \%$ height) from experiment with an ingoing gas at $800^{\circ} \mathrm{C}$ and approximately $30 \% \mathrm{O}_{2}$. (Online version in color.)

Table 4. Parameters used to describe the temperature profile in Fig. 3: average maximum temperature $(\operatorname{MaxT})$ in zone 2, average heating rate $\left(d T / d t_{400-M a x T}\right)$ in zone 2 and average time duration $\geq 1000^{\circ} \mathrm{C}$ and $1100^{\circ} \mathrm{C}$ (zone 2 and 3$)$.

\begin{tabular}{lccccc}
\hline \multicolumn{5}{c}{ Parameters (average data) describing thermal history as function of } \\
bed height \\
\hline \multirow{2}{*}{ Bed height } & Initial Temp. & MaxT & $d T / d t_{400-\operatorname{Max} T}$ & $\Delta t_{1} 000^{\circ} \mathrm{C}$ & $\Delta t_{1} 100^{\circ} \mathrm{C}$ \\
\cline { 2 - 6 } & ${ }^{\circ} \mathrm{C}$ & ${ }^{\circ} \mathrm{C}$ & ${ }^{\circ} \mathrm{C} / \mathrm{min}$ & $\min$ & $\min$ \\
\hline $27 \%$ (D) & 205 & 1180 & 100 & 5 & 3
\end{tabular}

riffle-splitter. Pellet samples for microscopic investigation were collected randomly from one of the sub-samples. Due to sampling errors, only one data point at $51 \%$ bed height from the experiment with approximately $13 \% \mathrm{O}_{2}$ in zone 2 was obtained. Wet-chemical titration with a $\mathrm{K}_{2} \mathrm{Cr}_{2} \mathrm{O}_{7}$ standard solution determined the concentration of ferrous ion $\left(\mathrm{Fe}^{2+}\right)$, and using Eq. (2), the oxidation degree was calculated based on the analysed $\mathrm{Fe}^{2+}$ for the green and indurated pellets from each experiment. The cold compression strength (CCS) was measured in accordance with ISO 4700: $2015,{ }^{26)}$ however, when the CCS was below 100 daN complementary measurements using the LKAB pellet multipress (PMP) instrument ${ }^{27}$ ) were performed. Pycnometry, using an Accupyc II 1340 and a GeoPyc 1360 instrument (Micromeritics Inc., USA), determined the porosities of green and indurated pellets.

$$
\text { Degree of oxidation }=\left(1-\left(\frac{F e^{2+} \text { Sample }}{F e^{2+} \text { Green pellets }}\right)\right) \cdot 100 \ldots
$$

Manually grinding each pellet to the pellet centre prepared the pellet samples for microscopic investigation. The pellet halves were then mounted in epoxy resin, and then vacuum impregnated. After hardening, the samples were ground and then polished down to a $1 \mu \mathrm{m}$ fineness, using alcohol-based diamond suspensions. All steps of the sample preparation were conducted using alcohol. A light optical microscope, Leica (DM 6000M), equipped with a Leica camera (DFC 295) and a motorised movable stage enabled the pellet microstructural examination. Using the mosaic feature of the image analysis software, 
Leica Application Suite LAS V4.5.0 Multistep, enabled the capture of images of the entire pellet cross section at a magnification of $\times 100$. These individual images with a size of $2048 \times 1536$ pixels were collected automatically and stitched together producing a mosaic picture of approximately $20000 \times 20000$ pixels $(14.3 \times 14.3 \mathrm{~mm})$. Additionally, we manually collected individual images at a larger magnification $(\times 200)$.

\section{Results}

\subsection{Effect of Oxygen Partial Pressure on the Oxidation Profile in a Pellet Bed}

When the oxidising gas comes into contact with the bed, the magnetite pellets begin to oxidise and exothermic heat is released. When the gas is introduced continuously from above (DD), the pellets at the top of the pellet bed maintain a similar temperature to the ingoing gas. The continuous gas flow transports the heat generated by oxidation at the top to the lower levels of the bed. Therefore, the pellet layers on the bottom experience a significantly warmer gas than the top layer; this creates different conditions for oxidation. Oxidation of the subsequent layers thus generates more heat, which transports further down the bed and so on. The varying temperature of the gas flowing through the bed, in combination with a varied initial pellet temperature, generates different temperature profiles in the bed. As a result, oxidation of the pellets at different bed heights progresses differently. Figure 4 shows simplified illustrations of the resulting oxidation degree throughout the pellet beds from the experiments with gas at $800^{\circ} \mathrm{C}$ and $\mathrm{O}_{2}$ levels of approximately $6 \%, 13 \%$ and $30 \%$, whereas, Table 5 lists the corresponding oxidation degree at each bed height (A-F). The light grey and black colours represent hematite and magnetite, respectively. Table 6 shows the achieved maximum temperature (MaxT) and heating rate $\left(\mathrm{dT} / \mathrm{dt}_{400-\mathrm{MaxT}}\right)$ for each bed height. As expected, the oxygen level at approximately $30 \% \mathrm{O}_{2}$ generates the bed with the highest oxidation degree, whereas the lowest is generated at approximately $6 \% \mathrm{O}_{2}$. As the representative pellet cross sections in Table 5 shows, non-oxidised pellet cores increase closer to the bottom of each pot. In the experiment with an ingoing gas at $800^{\circ} \mathrm{C}$ and approxi- mately $6 \% \mathrm{O}_{2}$, the highest oxidation degree is found at the top of the bed (at 100\% of the bed height). Whereas, the corresponding values for oxygen levels at approximately $13 \%$ and $30 \% \mathrm{O}_{2}$ are found at $76 \%$ and at $51 \%$ of the bed height, respectively. In the bed from the experiment with approximately $30 \% \mathrm{O}_{2}$, the macrostructures of pellets from the top of the bed (at $100 \%$ bed height) indicate complete oxidation; however, the oxidation degree is less than at lower bed heights (Table 5). Unlike at the top of the bed, more of the exothermic heat accumulates in the middle and lower parts of the bed, meaning that these pellets experience higher temperatures $\left(>1100^{\circ} \mathrm{C}\right)$ in combination with the higher oxygen level of approximately $30 \%$ $\mathrm{O}_{2}$ (Table 6).

Figure 5 illustrates the effect of increasing the ingoing gas temperature, as opposed to increasing the oxygen level, on the bed oxidation profile. The figure shows the resulting oxidation degree as a function of the bed height when the ingoing gas temperature is either $1100^{\circ} \mathrm{C}$ or $800^{\circ} \mathrm{C}$ and the oxygen level is approximately $6 \% \mathrm{O}_{2}$. The oxidation degree increases at the top of the bed resulting from the higher gas temperature, whereas at $5-76 \%$ of the bed height, the oxidation degree is similar regardless of the variation of the ingoing gas temperature. As shown in Table 6 , the pellets at $15-100 \%$ of the bed height reaches higher maximum temperatures when the ingoing gas temperature is higher, while the thermal history at $5 \%$ bed height is comparable for both of the ingoing gas temperatures. At $15-27 \%$ of the bed height, the heating rates in the bed exposed to the higher gas temperature and approximate $6 \% \mathrm{O}_{2}$ level are comparable to the heating rates at the same bed heights as when the ingoing gas is at $800^{\circ} \mathrm{C}$ and approximately $13 \% \mathrm{O}_{2}$ (Table 6).

\subsection{Microstructural Investigation-Various Oxidation Profiles}

The microstructural investigation of individual pellets from different bed heights shows that the oxidation, in terms of degree and mechanisms, varies significantly from one pellet layer (bed height) to another. Based solely on the oxidation profiles, all the obtained microstructures are categorised into three types:
$6 \%$ oxygen

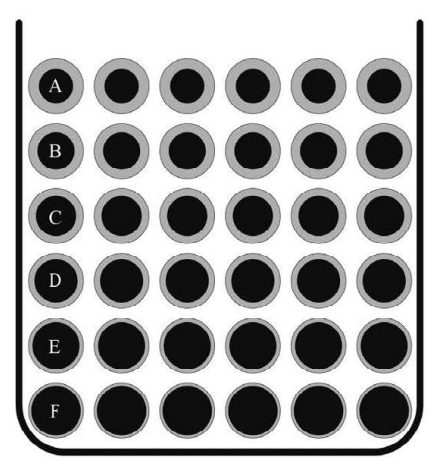

(a)
$13 \%$ oxygen

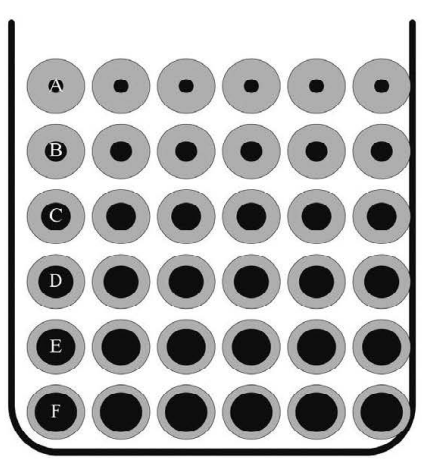

(b)

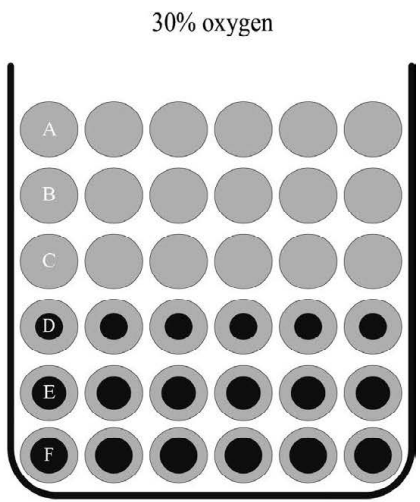

(c)

Fig. 4. Schematic illustration of pellet beds from the experiments with the ingoing gas at $800^{\circ} \mathrm{C}$ and different oxygen levels in zone 2. The light grey and black colours represent hematite and unoxidised magnetite, respectively. This illustration does not describe the real dimensions of the pellets or the pot furnace. 
Table 5. Representative pellet cross sections and average (chemically determined) oxidation degree at each bed height.

\begin{tabular}{|c|c|c|c|c|c|c|}
\hline \multicolumn{7}{|c|}{ Cross sections and average degree of oxidation as function of bed height } \\
\hline $\begin{array}{c}\% \mathrm{O}_{2} \text { of the ing. } \\
\text { gas in zone } 2\end{array}$ & & & & & & \\
\hline $\begin{array}{l}\text { Temp. of the ing. } \\
\text { gas in zone } 2\end{array}$ & & & & & & \\
\hline Bed height & $\begin{array}{l}\text { Pellet cross } \\
\text { section }\end{array}$ & $\begin{array}{l}\text { Degree of } \\
\text { oxidation }\end{array}$ & $\begin{array}{l}\text { Pellet cross } \\
\text { section }\end{array}$ & $\begin{array}{l}\text { Degree of } \\
\text { oxidation }\end{array}$ & $\begin{array}{l}\text { Pellet cross } \\
\text { section }\end{array}$ & $\begin{array}{l}\text { Degree of } \\
\text { oxidation }\end{array}$ \\
\hline$\%$ & & $\%$ & & $\%$ & & $\%$ \\
\hline $100(\mathrm{~A})$ & & $63 \pm 4$ & & $75 \pm 2$ & & $81 \pm 4.5$ \\
\hline $76(\mathrm{~B})$ & & $62 \pm 2$ & & $82 \pm 2$ & & $93.5 \pm 0.5$ \\
\hline $51(\mathrm{C})$ & & $57 \pm 2$ & & $\approx 77$ & & $96.5 \pm 0.5$ \\
\hline 27 (D) & & $38 \pm 1$ & & $63 \pm 9$ & & $94.5 \pm 0.5$ \\
\hline $15(\mathrm{E})$ & & $27.5 \pm 0.5$ & & $49 \pm 6$ & & $84 \pm 4$ \\
\hline $5(\mathrm{~F})$ & & $22 \pm 1$ & & $42 \pm 4$ & & $68 \pm 3$ \\
\hline
\end{tabular}

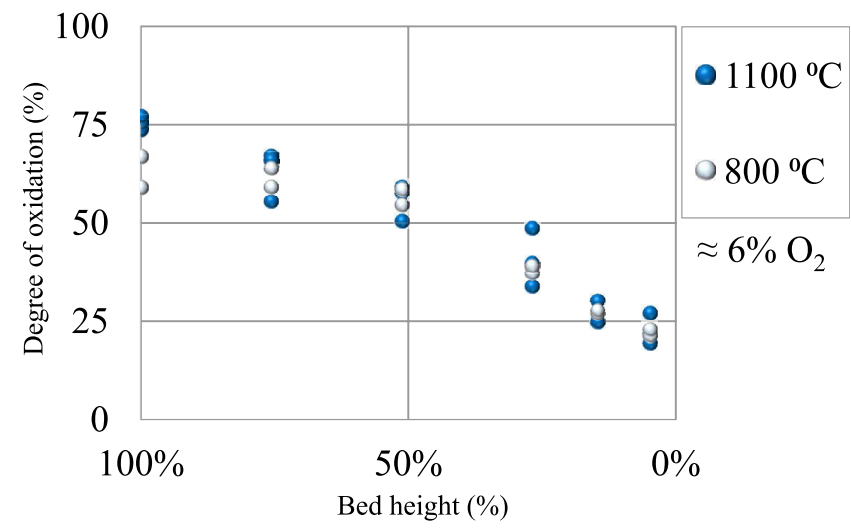

Fig. 5. Oxidation degree as a function of the bed height when the ingoing gas temperature is either $1100^{\circ} \mathrm{C}$ or $800^{\circ} \mathrm{C}$ and the oxygen level is approximately $6 \% \mathrm{O}_{2}$ in zone 2 . (Online version in color.)

\subsubsection{Type 1}

The macrostructures of Type 1 pellets indicate complete and homogenous oxidation. Although the microstructures confirm the homogenous oxidation, it also shows that particles larger than approximately $20 \mu \mathrm{m}$ are only partially oxidised (Fig. 6). Type 1 pellets are found at the top of the bed from the experiment with an ingoing gas at $800^{\circ} \mathrm{C}$ and approximately $30 \% \mathrm{O}_{2}$. Table 6 lists the thermal history of typical Type 1 pellets (see layer A, at 100\% bed height, from experiments with an ingoing gas at $800^{\circ} \mathrm{C}$ and approximately $30 \% \mathrm{O}_{2}$ in zone 2 ).

\subsubsection{Type 2}

The macrostructures of Type 2 pellets shows unreacted magnetite cores (Fig. 7). The microstructures reveal an oxide layer (hematite) consisting of completely oxidised 
Table 6. Average maximum temperature (MaxT) and average heating rate ( $\left.\mathrm{dT}^{\mathrm{d}} \mathrm{dt}_{400-\mathrm{MaxT}}\right)$ at each bed height.

\begin{tabular}{|c|c|c|c|c|c|c|c|c|}
\hline \multicolumn{9}{|c|}{ Parameters (average data) describing thermal history as function of bed height } \\
\hline $\begin{array}{c}\% \mathrm{O}_{2} \text { of the ing. } \\
\text { gas in zone } 2\end{array}$ & \multicolumn{2}{|c|}{$\approx 6 \% \mathrm{O}_{2}$} & \multicolumn{2}{|c|}{$\approx 13 \% \mathrm{O}_{2}$} & \multicolumn{2}{|c|}{$\approx 30 \% \mathrm{O}_{2}$} & \multicolumn{2}{|c|}{$\approx 6 \% \mathrm{O}_{2}$} \\
\hline $\begin{array}{l}\text { Temp. of the ing. } \\
\text { gas in zone } 2\end{array}$ & \multicolumn{2}{|r|}{$800^{\circ} \mathrm{C}$} & \multicolumn{2}{|c|}{$800^{\circ} \mathrm{C}$} & \multicolumn{2}{|c|}{$800^{\circ} \mathrm{C}$} & \multicolumn{2}{|c|}{$1100^{\circ} \mathrm{C}$} \\
\hline Bed height & $\operatorname{MaxT}$ & $d T / d t_{400-M a x T}$ & $\operatorname{MaxT}$ & $d T / d t_{400-M a x T}$ & MaxT & $d T / d t_{400-M a x T}$ & $\operatorname{MaxT}$ & $d T / d t_{400-M a x T}$ \\
\hline$\%$ & ${ }^{\circ} \mathrm{C}$ & ${ }^{\circ} \mathrm{C} / \mathrm{min}$ & ${ }^{\circ} \mathrm{C}$ & ${ }^{\circ} \mathrm{C} / \min$ & ${ }^{\circ} \mathrm{C}$ & ${ }^{\circ} \mathrm{C} / \min$ & ${ }^{\circ} \mathrm{C}$ & ${ }^{\circ} \mathrm{C} / \mathrm{min}$ \\
\hline $100(\mathrm{~A})$ & 812 & Not applicable & 819 & Not applicable & 841 & Not applicable & 1121 & Not applicable \\
\hline $76(\mathrm{~B})$ & 916 & Not applicable & 964 & Not applicable & 1053 & Not applicable & 1191 & Not applicable \\
\hline $51(\mathrm{C})$ & 969 & 50 & 1057 & 61 & 1140 & 93 & 1199 & 70 \\
\hline 27 (D) & 822 & 58 & 977 & 78 & 1180 & 100 & 1060 & 76 \\
\hline $15(\mathrm{E})$ & 758 & 59 & 862 & 75 & 1154 & 117 & 855 & 69 \\
\hline $5(\mathrm{~F})$ & 697 & 58 & 816 & 80 & 1115 & 128 & 730 & 65 \\
\hline
\end{tabular}

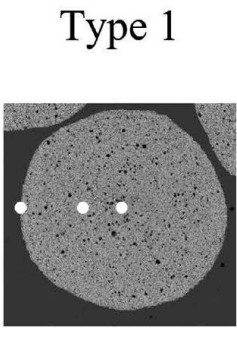

(a)

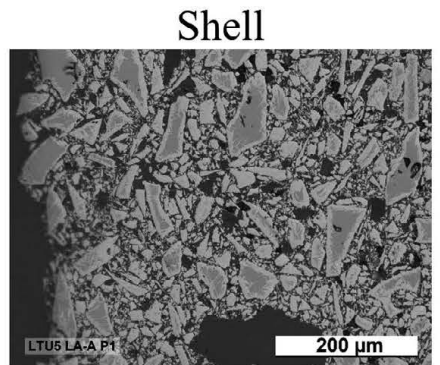

(b)

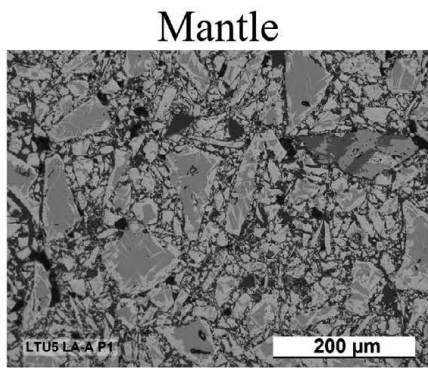

(c)

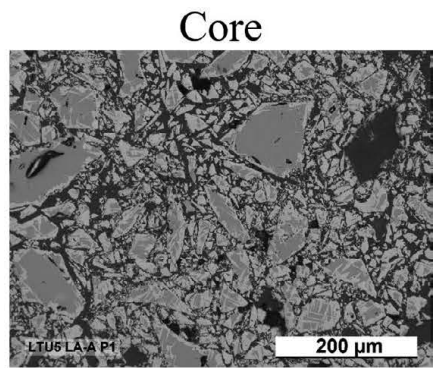

(d)

Fig. 6. Macro- and microstructure of reference pellets categorised as Type 1 . The images at $\times 200$ corresponds to the white markings in the pellet cross section image. Oxidised particles appear light grey, while unoxidised magnetite appear dark in the microstructure images.

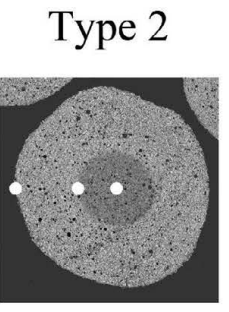

(a)

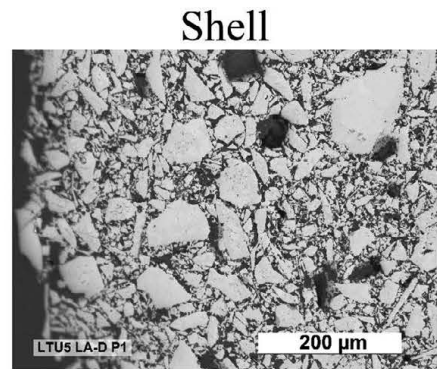

(b)

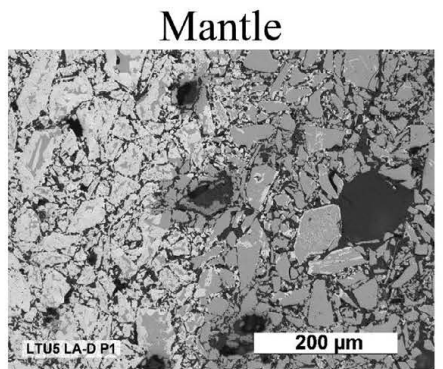

(c)

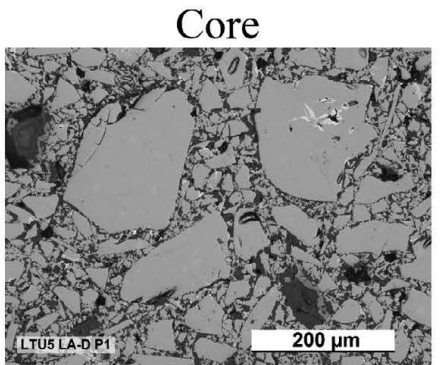

(d)

Fig. 7. Macro- and microstructures of reference pellets categorised as Type 2 . The images at $\times 200$ corresponds to the white markings in the pellet cross section image. Oxidised particles appear light grey, while unoxidised magnetite appear dark in the microstructure images.

particles, and shows that the oxidation front has grown topochemically from the shell into the pellet core, with a sharp/ distinct interface at the reaction front. The microstructures also show bridges between particles throughout the pellet cross section. Type 2 pellets are found in the middle or lower part of a pellet bed, where the measured maximum temperature (MaxT) is above approximately $1150^{\circ} \mathrm{C}$, for example, in the bed from the experiment with the ingoing gas at $800^{\circ} \mathrm{C}$ and approximately $30 \% \mathrm{O}_{2}$ at $27 \%$ of the bed height (Fig. 7). Table 6 lists the thermal history of typical Type 2 pellets (see layer D, at $27 \%$ bed height, from experiments with an ingoing gas at $800^{\circ} \mathrm{C}$ and approximately $30 \%$

\section{$\mathrm{O}_{2}$ in zone 2).}

\subsubsection{Type 3}

The macro- and microstructures of Type 3 pellets is a combination of Type 1 and Type 2. Macroscale visual observations show an oxidised pellet shell combined with an unreacted magnetite core. The microstructure reveals that the particles at the shell are only partially oxidised. There is a variation in the appearance of the microstructures within this group, resulting from how far the reaction front has progressed on a macro- and microscopic scale. Figure 8 depicts the oxidation variation at an earlier and 


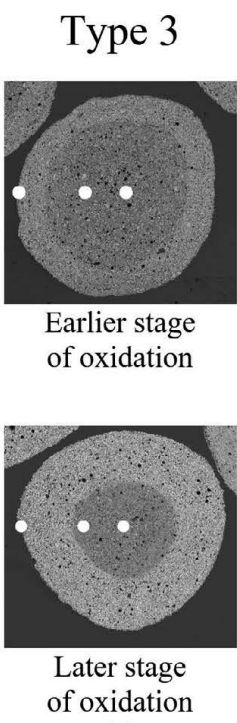

(a)
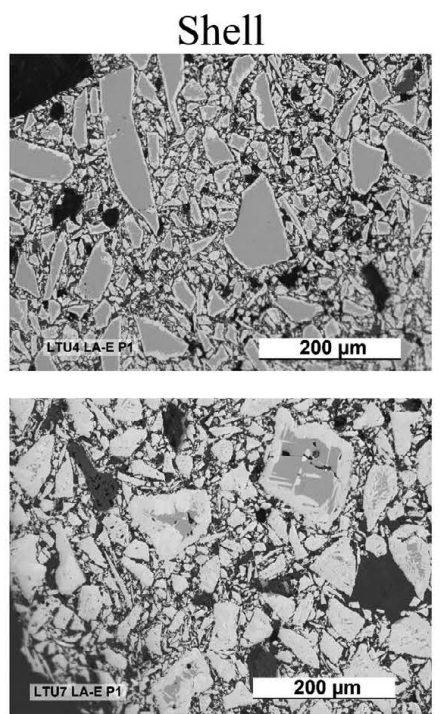

(b)
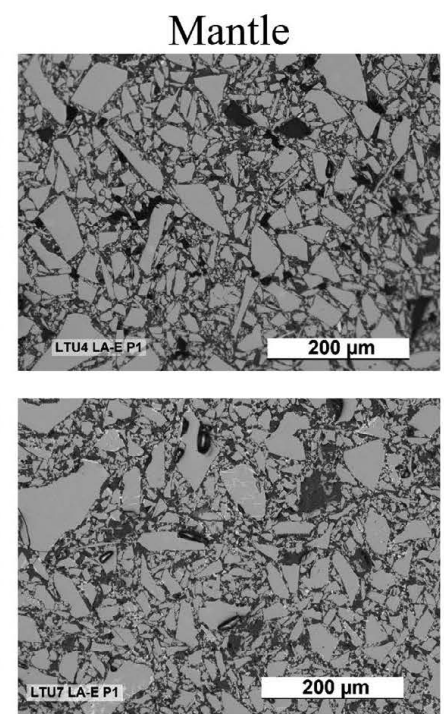

(c)
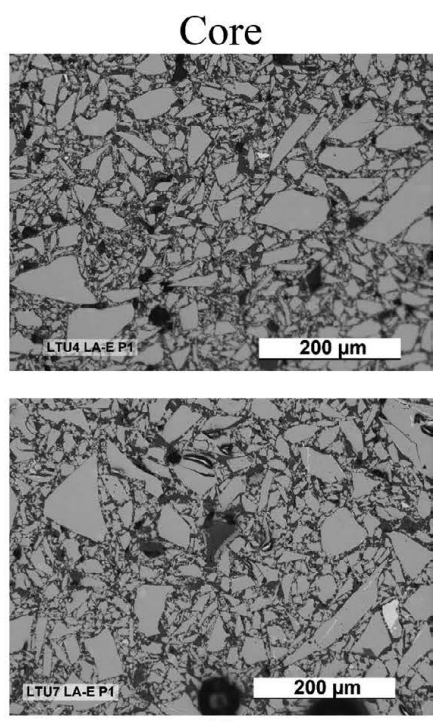

(d)

Fig. 8. Macro- and microstructures of reference pellets categorised as Type 3 . The images at $\times 200$ corresponds to the white markings in the pellet cross section image. Oxidised particles appear light grey, while unoxidised magnetite appear dark in the microstructure images.

a later stage. In the earlier stage of oxidation, the particles larger than approximately $20 \mu \mathrm{m}$ are only partially oxidised and in the later stage of oxidation, the particles larger than approximately $100 \mu \mathrm{m}$ are only partially oxidised. The oxidation front in the former case has not progressed as far as in the latter case (Fig. 8). Type 3 pellets are observed in all bed heights where the measured maximum temperature (MaxT) is below approximately $1150^{\circ} \mathrm{C}$, including at the top layer (at 100\% bed height) of the bed from the experiment with an ingoing gas at $800^{\circ} \mathrm{C}$ and oxygen levels at approximately $6 \%$ or $13 \% \mathrm{O}_{2}$. Table 6 lists examples of thermal histories of the typical Type 3 pellets, see layer E, at $15 \%$ bed height, from experiments with an ingoing gas at $800^{\circ} \mathrm{C}$ and approximately $13 \%$ or $30 \% \mathrm{O}_{2}$ in zone 2 .

\subsection{Influence of Oxygen Partial Pressure and Temper- ature on the Pellet Quality}

The current experimental setup enables the possibility of viewing each bed height (A-F) with its local conditions as a separate experiment, and thus enables the comparison of these pellet layers between themselves. This approach allows the influence of temperature and oxidation degree on pellet quality to be delineated, specifically, the oxidation degree and the CCS in an early stage of the pellet induration resulting from the interrupted experiments. The two comparisons below exemplify and illustrate this dependency:

\subsubsection{Pellet Oxidation at Different Thermal Histories and Similar Oxygen Levels}

The first comparison concerns pellets with different thermal histories (MaxT, heating rates and $\Delta \mathrm{t}_{1} 100^{\circ} \mathrm{C}$ ), but a similar oxygen level (approximately 30\% $\mathrm{O}_{2}$ ). In this case, the pellets $(C-0.30$ and $D-0.30)$ originate from the same bed (ingoing gas at $800^{\circ} \mathrm{C}$ in zone 2). C-0.30 pellets refers to pellets from $51 \%$ of the bed height with an initial temperature of approximately $375^{\circ} \mathrm{C}$, whereas $D-0.30$ pel- lets refers to pellets from $27 \%$ bed height with an initial temperature of approximately $205^{\circ} \mathrm{C}$. Figure 9 depicts the temperature profiles of the $C-0.30$ and $D-0.30$ pellets, and Table 7 summarises the data describing the thermal histories and pellet properties (oxidation degree, cold compression strength and porosity). The $D-0.30$ pellets experience a higher maximum temperature and a slightly faster heating rate than the $C-0.30$ pellets. The microscopic investigation shows complete oxidation of $C-0.30$ pellets, and that of the $D-0.30$ pellets shows Type 2 microstructures. The oxidation degree is similar for both the $C-0.30$ and $D-0.30$ pellets, and the $D-0.30$ pellets exhibit higher average cold compression strength.

\subsubsection{Pellet Oxidation at Similar Thermal Histories and Different Oxygen Levels}

The second comparison concerns pellets with comparable thermal histories (MaxT and $\Delta \mathrm{t}_{1} 100^{\circ} \mathrm{C}$ ), but different oxygen levels (approximately $6 \%$ and $30 \% \mathrm{O}_{2}$ ). The previous section describes the $D-0.30$ pellets. The other pellets, $C-0.06$, refers to pellets at $51 \%$ of the bed height from a bed exposed to a gas at $1100^{\circ} \mathrm{C}$ and approximately $6 \% \mathrm{O}_{2}$. The initial temperature of the $C-0.06$ pellets is approximately $375^{\circ} \mathrm{C}$. Figure 10 depicts the temperature profiles of the $C-0.06$ and $D-0.30$ pellets, and Table 7 summarises the data describing the thermal histories and pellet properties. The microscopic investigation shows that both the $C-0.06$ and $D-0.30$ pellets have Type 2 microstructures, regardless of the oxygen level variation of the ingoing gas, and despite the higher initial temperature of the $C-0.06$ pellets. For the $D-0.30$ pellets, the oxidation front has progressed further, the oxidation degree is higher and the average cold compression strength is also higher. In the current experiments, this is true for all pellets with comparable thermal histories and different oxygen levels. 


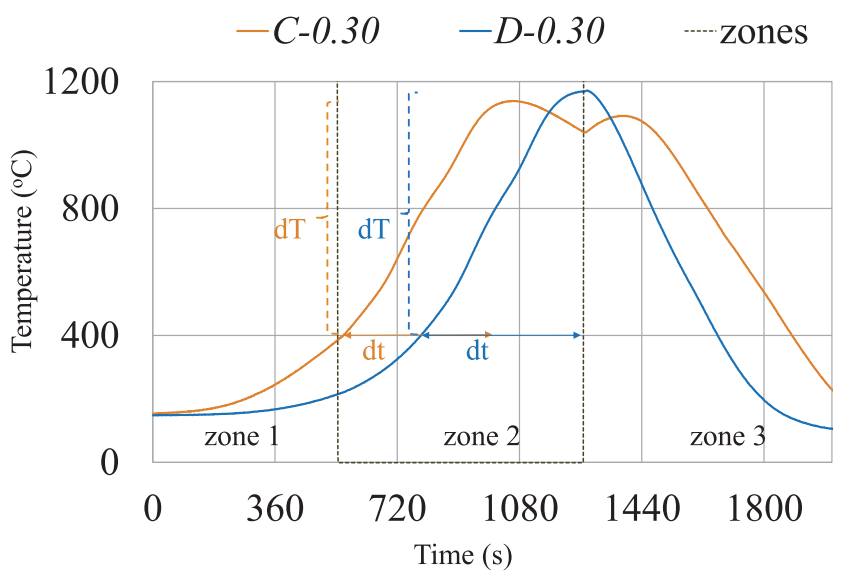

Fig. 9. Representative temperature profiles (X-Y plot) of $C-0.30$ (pellets at $51 \%$ bed height exposed to approximately $30 \%$ $\mathrm{O}_{2}$ in zone 2) and $D-0.30$ (pellets at $27 \%$ bed height exposed to approximately $30 \% \mathrm{O}_{2}$ in zone 2).

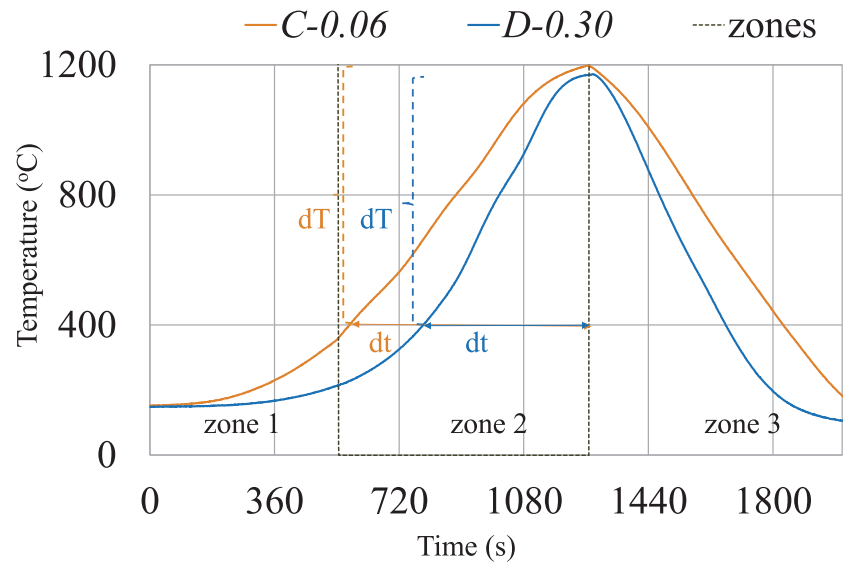

Fig. 10. Representative temperature profiles (X-Y plot) of C-0.06 (pellets at $51 \%$ bed height exposed to approximately $6 \%$ $\mathrm{O}_{2}$ in zone 2) and $D-0.30$ (pellets at $27 \%$ bed height exposed to approximately $30 \% \mathrm{O}_{2}$ in zone 2 ).

Table 7. Data describing the average thermal histories and pellet properties of the $C-0.30, D-0.30$ and $C$ - 0.06 pellets (average oxidation degree, average cold compression strength and average porosity), representative pellet cross sections and type of microstructure.

\begin{tabular}{|c|c|c|c|c|}
\hline Comparisons: & & $C-0.30$ & $D-0.30$ & $C-0.06$ \\
\hline Oxygen level & $\% \mathrm{O}_{2}$ & $\approx 30$ & $\approx 30$ & $\approx 6$ \\
\hline Gas temp. & ${ }^{\circ} \mathrm{C}$ & 800 & 800 & 1100 \\
\hline Gas flow (DD) & $\mathrm{kg} / \mathrm{h}$ & 250 & 250 & 250 \\
\hline Bed height & $\%$ & 51 & 27 & 51 \\
\hline Initial temp. & ${ }^{\circ} \mathrm{C}$ & 375 & 205 & 375 \\
\hline Max. temp. (MaxT) & ${ }^{\circ} \mathrm{C}$ & 1140 & 1180 & 1199 \\
\hline Heat rate $\left(d T / d t_{400-\operatorname{Max} T}\right)$ & ${ }^{\circ} \mathrm{C} / \mathrm{min}$ & 93 & 100 & 70 \\
\hline$\Delta \mathrm{t}_{1100^{\circ} \mathrm{C}}$ & $\min$ & $3-4$ & $3-4$ & $4-5$ \\
\hline \multicolumn{5}{|l|}{ Pellet cross section } \\
\hline Microstructure & Type & $\begin{array}{l}\text { Completely } \\
\text { oxidised }\end{array}$ & 2 & 2 \\
\hline Degree of Oxidation & $\%$ & $96.5 \pm 0.5$ & $94.5 \pm 0.5$ & $56 \pm 4$ \\
\hline Cold compression strength & $\mathrm{daN}$ & $121 \pm 4$ & $163 \pm 10$ & $113 \pm 12$ \\
\hline Porosity & $\%$ & 28 & 27 & 27 \\
\hline
\end{tabular}

\section{Discussion}

One common trend for all pellet beds from the current experiments is the variation of local conditions (thermal histories), leading to corresponding variations in the ratecontrolling steps and oxidation mechanisms. As previously described, the pellets are categorised into three groups, according to the obtained macro- and microstructure images (Type 1, 2 and 3). Generally, the resulting types are consistent with the oxidation mechanisms described by the grain model by Szekely et al. ${ }^{8)}$ and confirms the observations from single pellet oxidation experiments performed by other researchers. $^{2,15,21)}$ Figure 11 shows schematic representations of Type I, II and III oxidation mechanisms. The oxidation profile corresponding to homogeneous oxidation through the entire pellet, Type I, is likely to occur in pellets exposed to relatively low temperatures at the top of the bed and with a higher oxygen level. Under these conditions, solid-state diffusion is plausibly the rate-controlling step and increasing the temperature would significantly promote oxidation. Further down in the bed, Type II oxidation emerges when the temperature is high enough (above approximately $1150^{\circ} \mathrm{C}$ ), and neither the chemical reaction at the interface nor solid-state diffusion are the rate controlling steps. Instead, oxidation is controlled by the available oxygen at the oxidation front (that is, gas pore diffusion), and would thus improve from an increased oxygen level. The third case, Type III oxidation occurs in situations where the rate 


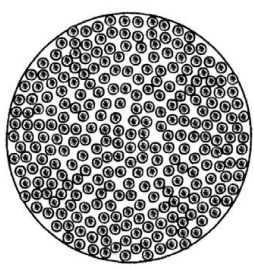

(a) Type $I$

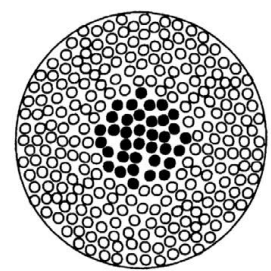

(b) Type $I I$ (c) Type III

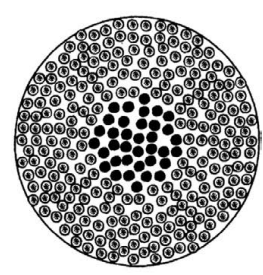

Fig. 11. Schematic sketch of the categorised types of oxidation profiles. The white and black colours represent hematite and unoxidised magnetite, respectively. This illustration does not describe the real particle geometry or particle size distribution.

of oxygen pore diffusion and solid-state diffusion are comparable. When oxidation is a mixed rate-controlled process, oxidation would be improved by increasing the temperature and/or the oxygen level. The oxygen level of the ingoing gas influences the oxidation profile throughout the bed. The increased oxygen level not only implies an increase in available oxygen, but it also means that the release and accumulation of exothermic heat at a certain bed height determines the thermal history of those pellets. The more efficient heat transportation to the lower parts of the bed, resulting from the higher oxygen level, indicates the potential for more effective oxidation throughout the bed within a shorter period of time. The faster bed scale oxidation confirms the potential to increase the production rate by increasing the oxygen level, which is in line with the previous findings from small-scale $\left(2 \mathrm{~kg}\right.$ pot) experiments by Haas et al. ${ }^{18)}$ The scale of the current experiments (approximately $100 \mathrm{~kg}$ pellets) allows us to observe the significant heat increase and faster oxidation that occurs at the lower bed heights because of the higher oxygen level. The variation in oxidation degree and mechanisms along the vertical direction of the bed, due to the varying local conditions, is another outcome from the results of the current experiments. To further evaluate the effect of varied oxygen levels on large bed scale, higher oxygen levels $\left(>30 \% \mathrm{O}_{2}\right)$ and its influence on the resulting bed temperature profiles is of high interest to investigate in the future.

To exemplify the type of oxidation profiles that occur when the oxidation is not the main source of heat, the comparison is extended to include a bed at a higher ingoing gas temperature $\left(1100^{\circ} \mathrm{C}\right)$ and a low oxygen level (approximately $6 \% \mathrm{O}_{2}$ ). When increasing the gas temperature alone, the oxidation degree at the top of the bed increases, whereas the higher gas temperature does not affect the oxidation degree significantly at the lower bed heights. In the durations of the current experiments, only half of the bed reaches the temperature of the ingoing gas. One reason for this could be that the amount of heat associated with the gas temperature is lower than the amount of theoretical heat release from the oxidation reaction. As the experimental setup allows for efficient heat transfer, most of the available heat associated with the ingoing down draft gas is probably transferred to the upper parts of the bed. Other than for comparative purposes, there is no benefit from oxidation at higher gas temperatures $\left(\geq 1100^{\circ} \mathrm{C}\right)$, in combination with a lower oxygen level, as it involves the risk of increasing the temperature in the upper part of the bed for an extended amount of time without sufficient access to oxygen.

In addition to the influence of oxygen level on the oxidation profiles, which is the primary focus in this study, this work also provides insight into the influence on pellet strength (CCS) during the initial stages of pellet induration. The thermal histories of pellets at comparable oxidation degrees affects their strength. The influence of increased temperature and duration at higher temperature on strength is expected and related to sintering that becomes significant at $1200^{\circ} \mathrm{C}^{7)}$ In the current experiments, in earlier stages of the induration, when pellets experience comparable thermal

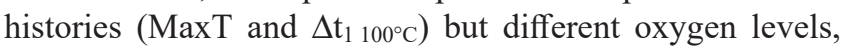
higher strength (CCS) is correlated to higher oxidation degree. The comparison of the $C-0.06$ and $D-0.30$ pellets (Fig. 10 and Table 7) exemplifies this trend. Bridging between particles during oxidation is known to influence pellet quality at lower temperatures, ${ }^{11,28)}$ and this study highlights the extended importance of oxidation at higher temperatures. The complete correlation between temperature, oxidation and strength at varied oxygen levels is complex and remains to be understood in detail.

The variation of microstructures in a bed exposed to a higher oxygen level (approximately 30\% $\mathrm{O}_{2}$ ), shows that pellets at the bottom of a bed oxidise according to different mechanisms than pellets at the top of the same bed. The difference in oxidation mechanisms is mainly due to the variation in temperature, whereas the oxygen level affects the oxidation rate. Oxidation at the top of the bed is promoted by an increase in temperature or possibly by reducing the flow rate of the ingoing gas. In contrast, higher oxygen levels promote the oxidation of pellets at the lower bed heights. It is likely that a lower gas flow rate would generate a bed with a higher oxidation degree in the upper part of the bed, as it would allow a greater accumulation of heat in this part of the bed than in the present case. Similarly, increasing the ingoing gas flow rate would likely transport the exothermic heat further down into the bed. Another variant would be to increase the ingoing gas temperature and oxygen level simultaneously, which could significantly improve the pellet strength. However, we recommend caution in this case because substantially high temperatures could lead to sintering before complete oxidation, resulting in inferior pellet quality. In addition, the oxidation rate is also highly dependent on particle size distribution. Smaller particles will oxidise faster ${ }^{8,29,30)}$ and the distribution will affect particle packing within the pellet and hence porosity. ${ }^{15)}$ Thus, particle size distribution is another relevant parameter to consider in future studies. From a bed scale perspective, besides material properties, the choice of increased oxygen level in combination with the ingoing gas temperature and flow rate will always constitute a balancing act, and the findings from this study can serve as a starting point.

\section{Conclusions}

In this study, we investigate the influence of varied oxygen levels (approximately 6\%, 13\% and 30\% $\mathrm{O}_{2}$ ) and ingoing gas temperature $\left(800^{\circ} \mathrm{C}\right.$ and $\left.1100^{\circ} \mathrm{C}\right)$ on the induration of a magnetite pellet bed in a pot furnace. Experiments with the specific material and experimental settings described in this article resulted in the observation of the following 
trends.

- Increasing the oxygen level results in a higher oxidation degree of the entire bed compared to beds exposed to lower oxygen levels.

- The local bed conditions generate pellets with three types of oxidation profiles, namely the homogenous oxidation of the entire pellet, an unreacted core with a distinct/ sharp interface and a completely oxidised shell, and an unreacted core with a partially oxidised pellet shell.

- Pellets experiencing comparable thermal histories show a similar oxidation mechanism, independent of the oxygen level in the gas. Thus, the oxygen partial pressure will only affect the extent of the oxidation.

- Increasing the oxygen level of the ingoing gas increases the pellet bed temperature and the oxidation degree at the lower bed heights more effectively than solely increasing the ingoing gas temperature.

- The higher oxygen level (approximately 30\% $\mathrm{O}_{2}$ ) leads to an increase in the oxidation degree at temperatures above $1100^{\circ} \mathrm{C}$, as well as increased strength (CCS) in the earlier stages of pellet induration.

\section{Acknowledgements}

This work has been conducted as part of the HYBRIT research project RP1. We gratefully acknowledge financial support from the Swedish Energy Agency. HYBRIT (Hydrogen Breakthrough Ironmaking Technology) is a joint initiative of the three companies SSAB, LKAB and Vattenfall with the aim of developing the world's first fossilfree ore-based steelmaking route.

The authors would like to acknowledge the support and guidance by the personnel at LKAB. In particular, Staffan Hedvall, Jörgen Rosenqvist and the team at the Pot furnace laboratory - Pernilla Nordin, Emma Nordström, Ebba Granström, Elisabeth KurthsDotter, Johan Forss, and MarieAnn Helin.

Ida Christin Eriksson, illustrator, is kindly acknowledged for assistance with the artwork in Fig. 4.

\section{REFERENCES}

1) LKAB, SSAB and Vattenfall: HYBRIT (Hydrogen Breakthrough Ironmaking Technology), https://www.hybritdevelopment.com, (accessed 2021-02-10). HYBRIT is a joint initiative by the three companies, LKAB (https://www.lkab.com), SSAB (https://www. ssab.com) and Vattenfall (https://group.vattenfall.com)

2) S. P. E. Forsmo, S.-E. Forsmo, P.-O. Samskog and B. M. T. Bjorkman: Powder Technol., 183 (2008), 247.

3) J. D. Zetterstrom: Report of Investigations, 4728, U. S. Department of the Interior, Bureau of Mines, Washington, D.C., (1950), 1.

4) Press release from the Government Offices of Sweden, Ministry of the Environment and Ministry for Foreign Affairs, https://www. government.se/press-releases/2016/11/paris-climate-agreemententers-into-force-today/, (accessed 2021-02-10).

5) United Nations, the Paris Agreement, https://unfccc.int/process-andmeetings/the-paris-agreement/the-paris-agreement, (accessed 2021$02-10)$.

6) K. Meyer: Pelletizing of Iron Ores, Springer-Verlag, Berlin, (1980), 48.

7) S. P. E. Forsmo: Ph.D. thesis, Luleå University of Technology, (2007), http://urn.kb.se/resolve?urn=urn:nbn:se:ltu:diva-26365, (accessed 2021-02-10).

8) J. Szekely, J. W. Evans and H. Y. Sohn: Gas-Solid Reactions, Academic Press, New York, (1976), 108.

9) V. M. Abzalov, V. I. Klein and B. P. Yur'ev: Steel Transl., 38 (2008), 421, Original publication: V. M. Abzalov, V. I. Klein and B. P. Yur'ev: Izv. VUZ Chernaya Metall., (2008), No. 6, 7 (in Russian).

10) S. R. B. Cooke and T. E. Ban: Trans. AIME, 193 (1952), 1053.

11) S. R. B. Cooke and W. F. Stowasser: Trans. AIME, 193 (1952), 1223.

12) P.-A. Ilmoni and J. Uggla: Jernkontorets tekniska råd, Meddelande, 217 (1955), 803 (in Swedish).

13) J. O. Edström: Jernkont. Ann., 141 (1957), 457.

14) A. R. Firth: Trans. Inst. Min. Metall. C, 116 (2007), 93.

15) D. Papanastassiou and G. Bitsianes: Metall. Trans., 4 (1973), 487.

16) P. O. Pape, R. D. Frans and G. H. Geiger: Ironmaking Steelmaking, 3 (1976), 138

17) L. Bentell and G. Mathisson: Scand. J. Metall., 7 (1978), 230.

18) L. A. Haas, J. C. Nigro and R. C. Moe: Report of Investigations, 9473, U. S. Department of the Interior, Bureau of Mines, Washington, D.C., (1993), 1.

19) B. E. Monsen, S. E. Olsen and L. Kolbeinsen: Scand. J. Metall., 23 (1994), 74.

20) H. J. Cho and P. C. Pistorius: Proc. Iron and Steel Technology Conf. and Exposition (AISTech), Association for Iron and Steel Technology, Warrendale, PA, (2012), 503.

21) M. Tang, H. J. Cho and P. C. Pistorius: Metall. Mater. Trans. B, 45 (2014), 1304.

22) T. K. S. Kumar, N. N. Viswanathan, H. Ahmed, A. Dahlin, C. Andersson and B. Bjorkman: Metall. Mater. Trans. B, 50 (2019), 150.

23) L. Doraiswamy and M. Sharma: Heterogeneous Reactions: Analysis, Examples, and Reactor Design, Vol. 1: Gas Solid and Solid-Solid Reactions, John Wiley \& Sons, Hoboken, NJ, (1984), 449.

24) H. J. Cho, M. Tang and P. C. Pistorius: Metall. Mater. Trans. B, 45 (2014), 1213.

25) T. K. S. Kumar, N. N. Viswanathan, H. Ahmed, A. Dahlin, C. Andersson and B. Bjorkman: Metall. Mater. Trans. B, 50 (2019), 162

26) ISO 4700: 2015(E), Iron ore pellets for blast furnace and direct reduction feedstocks - Determination of the crushing strength.

27) S. P. E. Forsmo, A. J. Apelqvist, B. M. T. Björkman and P.-O. Samskog: Powder Technol., 169 (2006), 147.

28) S. Song and P. C. Pistorius: ISIJ Int., 59 (2019), 1765.

29) G. Qiu, D. Zhu, J. Pan, C. Wang, Y. Guo, T. Jiang, C. Hu, J. Clout and F. Shu: ISIJ Int., 44 (2004), 69.

30) H. J. Cho and P. C. Pistorius: Proc. Iron and Steel Technology Conf. and Exposition (AISTech), Association for Iron and Steel Technology, Warrendale, PA, (2011), 507. 